Max-Planck-Institut für demografische Forschung

Max Planck Institute for Demographic Research

Konrad-Zuse-Strasse 1 - D-18057 Rostock · GERMANY

Tel +49 (0) 3812081 - 0; Fax +49 (0) 3812081 - 202;

http://www.demogr.mpg.de

MPIDR WORKING PAPER WP 2007-009

FEBRUARY 2007

\title{
Eligibility for Materniy Leave and First Birth Timing in Great Britain
}

Cordula Zabel (zabel@demogr.mpg.de)

This working paper has been approved for release by: Gerda Ruth Neyer (neyer@ demogr.mpg.de) Deputy Head of the Laboratory of Contemporary European Fertility and Family Dynamics.

(C) Copyright is held by the authors.

Working papers of the Max Planck Institute for Demographic Research receive only limited review. Views or opinions expressed in working papers are attributable to the authors and do not necessarily reflect those of the Institute. 


\title{
Eligibility for Maternity Leave and First Birth Timing in Great Britain
}

Cordula Zabel

\begin{abstract}
This paper examines the impact of maternity leave legislation on first birth timing in Great Britain. When maternity leave was introduced in Great Britain in 1976, the eligibility requirement for full-time employees was to have been working for the same employer for at least 2 years. Using data from the British Household Panel Survey (BHPS), this paper examines whether women postponed first birth in accordance with tenure requirements for maternity leave. Higher transition rates to first birth are found for those who had acquired enough employer tenure to qualify for maternity leave than for those who did not yet qualify. However, the causal role of maternity leave legislation for first birth timing is uncertain, since transition rates to first birth began to diverge by employer tenure even before 1976 .
\end{abstract}




\section{Introduction}

Family policies occasionally have impacts on processes of family formation, whether intended or unintended. When maternity leave was introduced in Great Britain in 1976, the eligibility requirement for full-time employees was to have been working for the same employer for at least 2 years. This paper examines whether this special eligibility requirement caused a postponement of first births. If eligibility regulations for maternity leave influence fertility timing, this would indicate a high level of importance of this right to employed women. From the perspective of theories of individual-level decision making, an effect on fertility timing would give evidence that people take macro-level policy changes into considerations when making life-course decisions. The regulations for maternity leave only had the potential to cause a shortterm postponement of births. However, even a postponement of about half a year could have contributed to the rise in age at first birth in Great Britain.

The first section of this paper gives an account of the development of maternity leave regulations in Great Britain. This will be followed by a review of previous studies on the relationship between maternity leave policy, employment, and fertility. Subsequently, the data that was used and the applied method of analysis will be discussed. Next, results of the empirical analyses will be presented. The conclusion then draws together the main findings.

\section{The development of maternity and parental leave regulations in the United Kingdom}

In the United Kingdom, as in some other countries, there has traditionally been a distinction between maternity leave and parental leave. Maternity leave is taken right around the birth of the child, while parental leave can be taken later and can also be taken by fathers. As a counterpart to maternity leave, paternity leave has also recently been introduced.

Unpaid maternity leave (in other words, the right of reinstatement into ones previous job) was introduced in 1976. This right was conditional on having worked for 2 years for ones employer the $11^{\text {th }}$ week before the expected week of childbirth, or 5 years if working for less than 16 hours a week. Employees who fulfilled these con- 
ditions had the right to return to work at any time until 29 weeks after childbirth. Starting in 1977, there were 6 weeks of maternity pay at $90 \%$ of the previous salary and 18 weeks of state-paid flat-rate maternity allowance.

In 1987, eligibility requirements for the flat-rate maternity allowance changed. It was now no longer necessary to have acquired any length of employer tenure to qualify for this benefit. However, the requirement was introduced to have been insured for a total of 6 months of employment in the previous year. Those who had not changed employers during those 6 months qualified for a higher level flat-rate. However, the right to retain ones job as well as the 6 weeks of maternity pay at $90 \%$ of previous earnings still depended on employer tenure. Now, the requirement was to have been employed with the same employer for 2 years (or 5 years for part-time employees) the $15^{\text {th }}$ week before childbirth.

Starting in 1994, there no longer were any differences in maternity leave regulations by hours of work. Furthermore, half of maternity leave became unconditional. All women now had a right to 14 weeks of leave, but those working for their employer for two years had a right to an additional 14 weeks of leave. If one was insured during the last year, one had a right to paid leave, though only for a maximum of 18 weeks. If 26 weeks of the insured employment were with the same employer into the $15^{\text {th }}$ week before the expected week of childbirth, one had a right to 6 weeks of maternity pay at $90 \%$ of previous income.

Unconditional leave was extended to 18 weeks in 2000, and women who had been continuously employed throughout the last year, even if there were employer changes, were eligible for an additional 11 weeks of leave. The regulations for maternity pay remained unchanged.

The present study period only runs to the end of 2000. Therefore, changes in maternity leave and pay regulations after the year 2000 will not be relevant for the empirical analyses. None-the-less, recent changes in maternity leave and pay will be briefly presented in the following in order to give an overview of current developments and in order to put the findings into context.

In 2003, for children born after 6 April 2003, more extensive leave regulations were introduced. Maternity leave was extended to 26 weeks paid and 26 weeks unpaid leave. The latter depended on having been continuously employed for 26 weeks the $14^{\text {th }}$ week before childbirth, though this did not necessarily have to be with the same 
employer. Eligibility for different forms of flat-rate maternity pay became dependent on income.

For mothers of babies born after 1 April 2007, all 52 weeks of maternity leave were made unconditional of employment duration. The length of maternity pay was extended to 39 weeks. However, to receive $90 \%$ income replacement for the first 6 weeks and an employer-paid flat-rate for the remaining period, one has to already have been employed with the same employer before the beginning of pregnancy. Women who do not fulfill this condition are eligible for a state-paid maternity allowance for 39 weeks (Department of Trade and Industry 2006; Department of Trade and Industry 2003; Gregg, Gutiérrez-Domènech, and Waldfogel 2003; European Commission 2002a; McRae 1991; Freedland 1976; Reid 1976; Dex et al. 1996).

Since 2003, fathers can now take two weeks paid paternity leave. The condition is that they need to have worked for their employer for 26 weeks the $15^{\text {th }}$ week before childbirth (Department of Trade and Industry 2006).

In addition to maternity leave and paternity leave, parental leave was introduced in December 1999. The difference to maternity and paternity leave is that parental leave can be taken at any time up to the child's $5^{\text {th }}$ birthday. Parental leave involves the right to 13 weeks unpaid leave per parent. Parents have to have been employed with the same employer for one year continuously (European Commission 2000b; European Commission 2002a; Department of Trade and Industry 2002; Department of Trade and Industry 2006). 
Table1: The development maternity leave and maternity pay in Great Britain

\begin{tabular}{|c|c|c|}
\hline & Maternity leave & Maternity pay \\
\hline 1976 & $\begin{array}{l}\text { - Introduction of maternity leave } \\
\text { Duration: until } 29 \text { weeks after childbirth } \\
\text { Condition: } 2 \text { years employer tenure the } \\
11^{\text {th }} \text { week before childbirth ( } 5 \text { years for } \\
\text { part-time employees) }\end{array}$ & \\
\hline 1977 & no changes & $\begin{array}{l}\text { - Introduction of maternity pay: } \\
6 \text { weeks at } 90 \% \text { of previous earnings; } 12 \text { weeks flat-rate } \\
\text { Condition: } 2 \text { years employer tenure the } 11^{\text {th }} \text { week before } \\
\text { childbirth ( } 5 \text { years for part-time employees) }\end{array}$ \\
\hline 1987 & $\begin{array}{l}\text { - Condition changed: } \\
2 \text { years employer tenure the } 15^{\text {th }} \text { week } \\
\text { before childbirth ( } 5 \text { years for part-time } \\
\text { employees) }\end{array}$ & $\begin{array}{l}\text { - Conditions changed: } \\
6 \text { weeks at } 90 \% \text { of previous earnings: } \\
\text { Condition: } 2 \text { years employer tenure the } 15^{\text {th }} \text { week before } \\
\text { childbirth }(5 \text { years for part-time employees) } \\
18 \text { weeks employer-paid flat-rate } \\
\text { (12 weeks if qualified for the } 6 \text { weeks at } 90 \%) \\
\text { Condition: insured employment for } 6 \text { months during the } \\
\text { previous year without employer changes by the } 15^{\text {th }} \\
\text { week before childbirth } \\
18 \text { weeks state-paid flat-rate } \\
\text { Condition: insured employment for } 6 \text { months during } \\
\text { the previous year by the } 15^{\text {th }} \text { week before childbirth }\end{array}$ \\
\hline 1994 & $\begin{array}{l}\text { - Introduction of } 14 \text { weeks unconditional } \\
\text { maternity leave } \\
\text { - } 14 \text { weeks additional leave } \\
\text { Condition: } 2 \text { years employer tenure by } \\
\text { the } 15^{\text {th }} \text { week before childbirth (both } \\
\text { full- and part-time employees) }\end{array}$ & $\begin{array}{l}\text { - Conditions changed: } \\
6 \text { weeks at } 90 \% \text { of previous earnings and } 12 \text { weeks em- } \\
\text { ployer-paid flat-rate (statutory maternity pay) } \\
\text { Condition: } 26 \text { weeks employer tenure the } 15^{\text {th }} \text { week } \\
\text { before child birth (insured employment) } \\
18 \text { weeks state-paid flat-rate } \\
\text { Condition: to not qualify for statutory pay; to have } \\
\text { been employed or self-employed for } 26 \text { weeks during } \\
\text { the } 66 \text { weeks before childbirth; to have earned an } \\
\text { average of at least } £ 30 \text { a week over a } 13 \text { week period }\end{array}$ \\
\hline 2000 & $\begin{array}{l}\text { - Unconditional leave extended to } 18 \\
\text { weeks } \\
\text { - } 11 \text { weeks additional leave: } \\
\text { Condition: one year continuous } \\
\text { employment by the } 11^{\text {th }} \text { week before } \\
\text { childbirth }\end{array}$ & no changes \\
\hline 2003 & $\begin{array}{l}\text { - Unconditional leave extended to } 26 \\
\text { weeks } \\
\text { - } 26 \text { weeks additional leave: } \\
\text { Condition: continuous employment for } \\
26 \text { weeks into the } 14^{\text {th }} \text { week before } \\
\text { childbirth }\end{array}$ & $\begin{array}{l}\text { Extension: } \\
6 \text { weeks at } 90 \% \text { of previous earnings and } 20 \text { weeks } \\
\text { employer-paid flat-rate (statutory maternity pay) } \\
\text { Conditions unchanged } \\
26 \text { weeks state-paid flat-rate } \\
\text { Conditions unchanged } \\
\end{array}$ \\
\hline 2007 & $\begin{array}{l}\text { - Unconditional leave extended to } 52 \\
\text { weeks }\end{array}$ & $\begin{array}{l}\text { - Extension: } \\
6 \text { weeks at } 90 \% \text { of previous earnings and } 33 \text { weeks em- } \\
\text { ployer-paid flat-rate (statutory maternity pay) } \\
\text { Conditions unchanged } \\
39 \text { weeks state-paid flat-rate } \\
\text { Conditions unchanged }\end{array}$ \\
\hline
\end{tabular}




\section{Maternity leave regulations, employment, and fertility}

Maternity leave regulations can strongly influence mothers' employment trajectories by guaranteeing job retention and thus enabling a smooth return to employment. Several studies have investigated links between changes in British maternity leave policies and levels of maternal employment. This section will set out by reviewing some important findings in this respect. Given that access to maternity leave is indeed important for employment outcomes, women will be likely to draw this into consideration when making fertility decisions. However, very little research on Britain has dealt with implications of changes in maternity leave for levels of fertility. For Scandinavian countries by contrast, the connection between maternity leave regulations and fertility has been very closely examined. The second part of this section will summarize findings on fertility effects of maternity leave regulations in Scandinavian countries and discuss implications for the British context.

\subsection{Research on maternity leave and returns to employment in Great Britain}

Most descriptive results show positive effects of having taken maternity leave on the probability of returning to employment in the medium- to long-term. For instance, in initial analyses, McRae (1993) finds a positive effect of having taken maternity leave on the odds of returning to employment by a few weeks after the end of the standard leave period. One might however suspect that those women who qualify for maternity leave are a select, particularly work-oriented group. Indeed, in a model controlling for both the receipt of maternity pay and employment experience, the effect of maternity leave on the odds of returning is no longer significant. The problem here though is that effects of employment experience and maternity leave are extremely difficult to separate, since employer tenure is the main criterion for eligibility to maternity leave. McRae (1993) uses data from a survey of women who gave birth in December 1987 and January 1988. Interviews were conducted 8 to 9 months after birth. Statutory maternity leave at the time ran until 29 weeks after birth. The time of interview thus had been set to a few weeks after the end of maternity leave.

Waldfogel, Higuchi, and Abe (1999) analyze data from the National Child Development Study (NCDS), the respondents of which are 1958 cohort members last 
interviewed in 1991 when they were 33. The authors find positive effects of eligibility to maternity leave on job retention at 12 months after birth, which at the time was about half a year after the end of maternity leave. In their model, the authors control for education, birth order, and the mother's age at the birth of the child. When studying the effect of maternity leave coverage on job retention separately by educational groups, the authors find significantly positive effects for mothers with A-levels but no university degrees, and for mothers with lower levels of education. However, they find no effect for mothers with university degrees. It is likely that women with university degrees had access to contractual leave schemes provided voluntarily by their employers even if they had not yet acquired enough employer tenure to qualify for statutory maternity leave. In this study as well though, as soon as controls for employment experience are included, the positive effect of eligibility to maternity leave on job retention disappears for all educational groups.

Geisler (2006) analyses data from the Millennium Cohort Study (MCS), which provides information on children born in 2000 and 2001 as well as on their families. Most families were interviewed in the $9^{\text {th }}$ month after the birth of the child, but the date of the interview could range from the $8^{\text {th }}$ to the $11^{\text {th }}$ month after birth. Geisler (2006) analyzes the timing and probability of (re-)entering employment within the study period. In descriptive analyses, the author finds practically no difference between educational groups in return patterns before the end of statutory maternity leave and pay, which ran to 18 weeks after childbirth. After 18 weeks, risks of return are higher for women with medium and high education than for those with low education or no educational degree. Up until the end of additional leave at 29 weeks, the development is very similar for medium and highly educated women. After this time point, women with high education experience higher risks of return than those with medium education, and by the end of the observation period, a higher percentage of highly educated women, about $70 \%$, than women with a medium level of education, about $60 \%$, have returned. Of women with no or low education, $44 \%$ have returned. Higher levels of education seem to be associated with eligibility for longer lengths of leave, higher rates of return after the end of these leave periods, and altogether higher probabilities of having returned by the end of the observation period. Higher educated women's higher probabilities of being employed before birth may however also play a part here. 
Geisler (2006) also finds that mothers who received no maternity pay at all were at first the quickest to return, but by the end of the study period, at 8 to 9 months after birth, the least likely to have reentered employment at all. This contrasts with the finding by McRae (1994) that those who received no maternity pay at all were the most likely to return. However, McRae (1994) controls for a number of variables that are closely intertwined with the eligibility for maternity pay, such as employment experience, whether maternity leave was taken, as well as a number of supplementary benefits provided by employers.

Dex, Joshi, Macran, and McCulloch (1998) investigate the long-term impact of maternity leave on employment careers. Analyzing data from the National Child Development Study (NCDS), a survey of 1958 cohort members interviewed at age 33 in 1991, the authors find a positive effect of having interrupted employment for no longer than 8 months around the birth of the first child on employment in any given subsequent month up until age 33. A large number of control variables was included, such as women's father's occupational background, women's level of education, partner's level of education, age at first birth, housing tenure at $1^{\text {st }}$ birth, type of housing, attitude to work at age 23 , imputed wage, age of the first child, age of the youngest child, number of children, partnership status, and the national unemployment rate. The authors assume that those women who interrupted employment for no longer than 8 months were on maternity leave. It is of course possible that women without access to maternity leave also returned to employment quickly and were erroneously counted as being on maternity leave.

Gregg, Gutiérrez-Domènech, and Waldfogel (2003) study whether the employment gap between married women with and without children has narrowed across the time during which maternity leave was expanded in Great Britain. The authors use data from the General Household Survey (GHS), an annual survey of households in Great Britain, for the years 1974-2001. They find increases in mothers' employment especially when children are less than 1 year old. Mothers of each successive cohort of children are found to have contributed to closing the employment gap relative to women without children. The authors conclude that after the introduction of maternity leave, mothers have increasingly made use of this right, and have thus been better able to return to employment while their child was still very young.

The studies reviewed so far have all analyzed the effect of maternity leave on mothers' returns to employment. Very little research for Great Britain has been done 
on effects of maternity leave on fertility. One study that does look into potential effects on fertility is a cross-country macro-level time series analysis by Gauthier and Hatzius (1997). The authors use time series data from 22 countries for the years 1970 to 1990. Neither in a model including all countries, nor in models for country subgroups do the authors find any significant effect of the length of maternity leave or the height of maternity pay on the total fertility rate. However, it is always difficult to identify individual-level causal effects on the macro-level. In the next section, studies using micro-level models that have found effects of maternity pay policy on fertility for Scandinavian countries will be reviewed.

This section has reviewed studies on Britain that have mostly focused on impacts of maternity leave and pay on mothers' return patterns to employment. Positive effects of taking maternity leave on probabilities of returning to employment have generally been found, so long as employment experience was not controlled for. Because employer tenure was the main eligibility criterion for maternity leave, effects of maternity leave and employment experience are very difficult to separate. At least judging from models that do not include employment experience, though, it appears that women have reason to expect maternity leave to be important for maintaining continuity in their careers. Therefore, an hypothesis that will be tested in section 5 is that women postponed first birth until they had acquired enough employer tenure to qualify for maternity leave. In what way receiving maternity pay should influence employment continuity is less clear. However, maternity pay can be expected to be very important for new mothers' ability to support their family. Therefore, eligibility for maternity pay can be expected to be important for first birth timing as well.

Because little research has been done on fertility effects of maternity leave policy in Britain, the next section will review studies on Scandinavian countries, where this relationship has been studied quite closely.

\subsection{Effects of maternity pay policy on fertility in Scandinavian countries}

Several studies for Scandinavian countries have found effects of changes in maternity pay policy on the timing of fertility. In Sweden, the level of income compensation during parental leave is linked to the length of the birth interval. This has been found to influence the timing of higher order childbearing (Hoem 1993, Andersson 2004). 
Studies on these policy effects on processes of family formation will be reviewed in this section.

In Sweden, the height of income replacement during parental leave depends on ones previous level of income. In the 1970s, a policy reform was introduced to the effect that parents can keep the level of income compensation they previously received during parental leave after having a child even after having further children, as long as the children's birth dates are spaced closely enough. Thus, if a parent initially works full-time before having children, but then switches to part-time or does not return to work at all after having a child and then has a further child, income replacement is still based on their level of income before the first birth, if the next child is born in close sequence. The maximum length of the birth interval that allowed continued eligibility for the previous level of compensation was 12 months in 1974 (or up to 15 months including sick leave and vacation), and was extended to 15 months in 1979, 24 months in 1980, and 30 months in 1986 (Hoem 1990).

Hoem (1990) shows that second and third birth rates in Sweden increased more strongly in the 1980s at short than at longer durations after the previous birth. Increases in $2^{\text {nd }}$ and $3^{\text {rd }}$ birth rates were strongest for mothers whose previous child was 1 or 2 years old. Hoem (1990) argues that this is likely to be a response to the extension of the eligibility interval to 24 (and later 30 months), as it then became feasible to plan to have a further child within this time. Hoem (1993) looks into the effects of these policy changes in more detail. Examining higher order birth rates by calendar time and age of the youngest child, standardized for the age of the mother at the previous birth, he finds that birth rates increased at all ages of the youngest child after 1977. However, the increase here is especially strong for women whose youngest child is only 1 year old. This is the only group to benefit from the extension of income replacement. After 1985, when the eligibility interval was extended to 30 months, there is a much stronger increase in $2^{\text {nd }}$ and $3^{\text {rd }}$ birth rates for mothers of 2-year-olds than for mothers of $2 \frac{1}{2}$ year-olds. It is likely that the former are responding to their new eligibility for continued income replacement after having a further child.

Andersson, Hoem, and Duvander (2006) study differences between social groups in the effect of this policy reform on fertility timing. They find that all educational groups reacted equally strongly to the extension of the eligibility interval from 24 to 30 months in 1986. Comparing the years 1981 and 1990, they find an increase in $2^{\text {nd }}$ and $3^{\text {rd }}$ birth risks at durations of less than 30 months after the previous birth for 
all educational groups. Looking specifically at the ratios of $2^{\text {nd }}$ and $3^{\text {rd }}$ birth risks at durations of 24-29 months to $2^{\text {nd }}$ and $3^{\text {rd }}$ birth risks at 30-35 months after the previous birth, an equally large increase was found for all educational groups. That there are no differences in reactions to the policy reform between educational groups can be taken to indicate that there was no inequality in the spread of information about the reform to the different educational groups.

Andersson, Hoem, and Duvander (2006) also compared reactions to the policy reform between Swedes, immigrants from Nordic countries, and Non-Nordic immigrants. They found very similar patterns for Swedish-born women and Nordic immigrants. This is likely to be related to Swedes' and Nordic immigrants' very similar cultural backgrounds and degrees of attachment to the labor market. For Non-Nordic immigrants, however, the authors found no reaction to the policy reform in terms of birth timing. An explanation might be that women from Non-Nordic countries are less attached to the labor market. Alternatively, if they do not follow the Swedish pattern of switching to part-time work after becoming mothers but continue to work full-time, they would not profit from closer birth spacing either.

To further verify whether the shortening of birth intervals in Sweden in the 1980s was really related to the reform of maternity pay policy, and not just a result of women's generally increasing attachment to the labor market, Andersson (2002) compares the development of fertility timing patterns in Sweden to those in neighboring Norway. Between the years 1980 and $1990,2^{\text {nd }}$ birth rates by the age of the first child did not change in Norway, although they increased at short birth intervals in Sweden. This is further evidence that it was the maternity pay reform that was responsible for the shortening of the birth intervals in Sweden. This is further supported by the development of third birth timing in the two countries. Andersson (2002) finds that while $3^{\text {rd }}$ birth risks increased in both countries, they did so much more strongly at short birth intervals in Sweden than in Norway. Andersson (2004) additionally compares trends in birth timing in Denmark to those in Sweden. In Sweden the $2^{\text {nd }}$ birth pattern by age of the first child completely changed between 1980 and 1995, with increases at short durations after the first birth only. In Denmark on the other hand, only the level of $2^{\text {nd }}$ birth risks increased, while the pattern of $2^{\text {nd }}$ birth risks by age of the first child remained the same. This gives further evidence of an impact of the special policy change in Sweden on fertility timing. 
The studies reviewed in this section provide evidence of family policy effects on fertility in Sweden. The empirical analyses that will be presented in the following aim to investigate whether the special requirements for maternity leave similarly affected first birth timing in Great Britain. In contrast to the maternity pay policy in Sweden that constituted a 'speed premium', as it is popularly referred to (Andersson et al. 2006), the maternity leave regulations in Great Britain can be expected to have caused a postponement of births. The policies in the two countries have in common that the group of people to whom they apply is very closely defined. Therefore, possible effect should be easily identifiable in terms of differences in fertility patterns between the group to whom the regulation applies and those to whom it does not apply.

\section{Data and Method}

The data used for this study is from the British Household Panel Survey ${ }^{1}$ (BHPS). The BHPS began in 1991 and respondents are surveyed once a year. The BHPS also includes complete retrospective employer and fertility histories, which were collected in waves 2 and 3. For the following analyses, retrospective parts of the BHPS were combined with panel data. The study period refers to the years 1955 to 2001.

There are a few problems with the retrospective employer data used here that had to be dealt with. One problem is that we do not know exactly when a person gained a certain school degree, we only know which was the highest degree achieved and when they left school for the first time. However, as most people have finished school education by the age of 20, it should be safe to assume the highest level of school education after that age, if the respondent had left school by then. A further problem is that it is not possible to distinguish whether a person is unemployed or has returned to education after having left education for the first time. Up to about 22 years of age, many of those who are not employed are in education. After that age, the proportion of the not employed who are in education is much lower. For these reasons, the analyses for the effect of employer tenure on first birth risks were restricted

\footnotetext{
${ }^{1}$ The BHPS data used in this study were made available through the ESRC Data Archive. The data were originally collected by the ESRC Research Centre on Micro-social Change at the University of Essex (now incorporated in the Institute for Social and Economic Research). Neither the original collectors of the data nor the Archive bear any responsibility for the analyses or interpretations presented here.
} 
to women over 22 years of age. This leaves a sample size of 2560 . During the study period, 1615 first children were born.

The method of analysis used is event history analysis. The formula for the model that was estimated is the following:

$\ln \mathrm{h}_{\mathrm{i}}(\mathrm{t})=\mathrm{y}(\mathrm{t})+\sum_{k=1}^{m} \beta_{k} w_{i k}(t)$

The dependent variable is the log risk of first conception $\ln h_{i}(t)$. The date of first birth was backdated by 9 months. This was done in order to study the decision to have a first child. Women's employment status often changes between the beginning of pregnancy and the date of birth. Therefore, in order to get the correct causal order of events, it is important to take into account the employment characteristics at the time the decision to have a first child was made. The baseline duration used is age $(t)$, measured in time since the respondent turned 16. Accordingly, $y(t)$ is the log baseline risk of first conception. Independent variables, given by $w_{i k}(t)$, are educational attainment as well as an interaction between time period, employment status, and employer tenure. The categories used for educational attainment are no school degree or CSE 25, GCSE D-G, or O-level D-E ('no/ low education'), CSE 1, GCSE A-C, O-level before 1975, or O-level A-C ('medium education'), higher school certificate or A-level ('high education'). A table with occurrences and exposures for the independent variables is included in the appendix.

\section{Empirical Results}

In the following, the hypothesis is tested that women in Great Britain postponed first pregnancy until they had accumulated enough tenure to meet the requirement for maternity leave, once it was introduced in 1976. As outlined above, for full-time employees, the requirement for eligibility was that one had to have been employed for 2 years with ones employer until the $11^{\text {th }}$ week before the expected week of childbirth. That means that mothers were eligible for maternity leave if they were employed with the same employer for 18 months when they became pregnant. Thus, the hypothesis is that after 1976, when maternity leave was introduced, risks of transition to first preg- 
nancy were higher when women had more than 18 months of employer tenure than when they had less than 18 months of employer tenure. This type of a pattern is not expected for the time period before 1976, because there was not yet any incentive to postpone first pregnancy at that time. After 1994, tenure effects on risks of first pregnancy are expected to have become weaker, since 14 weeks of leave were now available without any tenure requirements.

Risks of first pregnancy have generally declined quite strongly across the study period, between 1955 and 2001. It is likely though that the availability of maternity leave made the decision to have a first child easier. Thus, a further hypothesis is that risks of first pregnancy did not decline as strongly across time for women who were eligible for maternity leave as for those who were not.

Table 1 shows the results of the model estimated for the risk of transition to first pregnancy. Figure 1 illustrates the effects of time period and employer tenure for women who were employed full-time. As one can see, before maternity leave was introduced in 1976, differences in risks of first pregnancy were not very large before compared to after 18 months of employer tenure. Rerunning the model with altered reference categories shows that first birth risks before and after 18 months of tenure were not significantly different before 1976. This is in line with the expectations, since there is not yet any incentive to postpone first pregnancy until after 18 months of employer tenure. This changes as soon as maternity leave is introduced in 1976. Between 1976 and 1994, there is indeed some indication that full-time employed women postponed first pregnancy until they had acquired at least 18 months of employer tenure. At least 18 months of employer tenure were needed at the beginning of pregnancy in order to meet the maternity leave requirement of having 2 years of employer tenure the $11^{\text {th }}$ week before birth ${ }^{2}$. Table 1 shows that first birth risks are significantly higher before than after 18 months of tenure between 1976 and 1994. After 1994, then, half of maternity leave became available without any tenure requirements. This should strongly decrease the incentive to postpone first birth. As might be expected, figure 1 shows that after 1994, employer tenure no longer had a strong influence on risks of first pregnancy, much like the time before 1976, before maternity leave was introduced.

\footnotetext{
${ }^{2}$ Between 1987 and 1994, actually 19 instead of 18 months of tenure were necessary at the beginning of pregnancy, since now the requirement was to have had 2 years of tenure the $15^{\text {th }}$ week before childbirth. However, even if 19 months of tenure were required to be eligible for maternity leave after 1987, this still implies that women would have to postpone the decision to have a child for at least 18 months.
} 
Figure 1 shows that for the first 18 months of employment with a new employer, risks of first pregnancy were lower in the time period 1976-1994 than before 1976. Thus it might appear that during the time-period 1976-94, the conditions for maternity leave had the effect of reducing risks of transition to first pregnancy at the beginning of employment with a new employer. However, first birth risks declined in general across these time periods. Would it therefore be more accurate to say that first birth risks did not decline as strongly for women who were eligible for maternity leave as they would have had maternity leave not been introduced at all? Indeed, while the risk of first pregnancy decreased by $22 \%$ between the time period prior to 1976 and the time period 1976-1994 for women who were not employed full-time, there was hardly any change in first birth risks for full-time employed women with more than 18 months of tenure. This might indicate that the introduction of maternity leave for women with more than 18 months of tenure actually counteracted the general time trend of declining first birth risks. On the other hand, the decline in first birth risks for full-time employed women with less than 18 months of tenure was also somewhat weaker than was generally the case for women not employed full-time. Looking at the time period after 1994, one can see that risks of first pregnancy decreased substantially less strongly for women employed full-time, both with more and less than 18 months of tenure, than would be expected given the time trend for all other women. This might indicate that after 1994, lifting the tenure requirement for maternity leave reduced the decline in first birth risks for full-time employees in general.

The results shown in table 2 and figure 2, though, cast some doubt onto the causal role of maternity leave for first birth timing in Great Britain. In the model shown in table 2, a more detailed measure of time period was interacted with employment status and tenure. As illustrated in figure 2, first birth risks began to diverge between women with less than 18 months and those with more than 18 months of tenure even before 1976, before maternity leave was introduced. In the period between 1965 and 1976, differences in first birth risks by tenure were quite large already. It is not clear what could have caused this divergence. Thus, it is also not clear whether the differences in first birth risks by tenure after 1976 were actually related to the maternity leave regulations introduced then, or were of some other origin. 


\section{Figure 1:}

relative risk of first pregnancy for full-time employees by time period and tenure (plot of estimates shown in table 1)

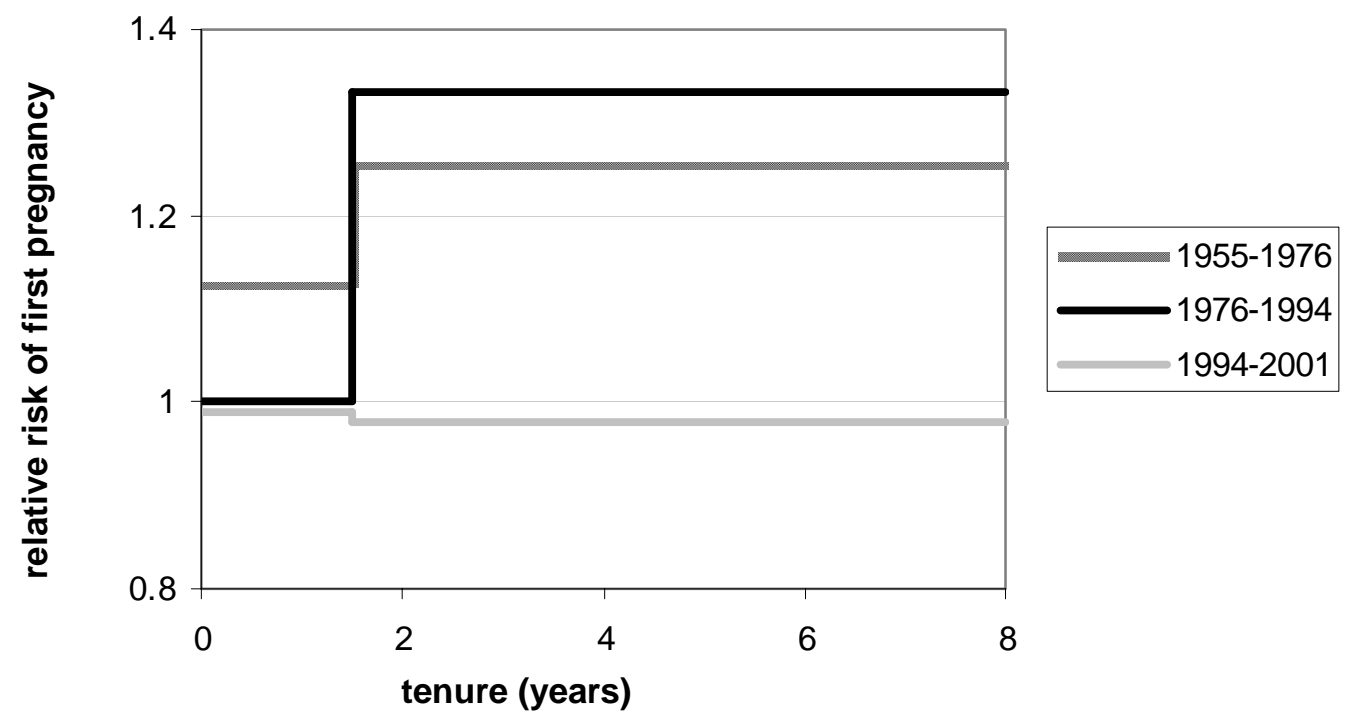




\section{Table 1}

Risk of transition to first pregnancy

age (baseline)

Absolute risk

22-24

0.0077

25-29

0.0080

30-34

0.0056

35-39

0.0022

40-44

0.0003

relative risks

time period (not full-time employed)

1955-1976

1976-94

1994-2001

0.78 *

employment status

self-employed

$0.50^{* * *}$

full-time employed

1.29

part-time employed

1.82

not employed

$1.61^{* * *}$

employed, status unknown

$2.18^{* * *}$

tenure/ period (full-time employed)

$<18$ months; before 1976

1.13

$>=18$ months, before 1976

1.25

< 18 months; 1976-94

$>=18$ months; $1976-94$

$<18$ months; $1994-2000$

0.99

$>=18$ months; $1994-2000$

0.98

\section{Education}

no/low education

medium education

high education

education missing

$0.76^{* \star *}$

0.84 
Figure 2:

relative risk of first pregnancy for full-time employees by time period and tenure (plot of estimates shown in table 2)

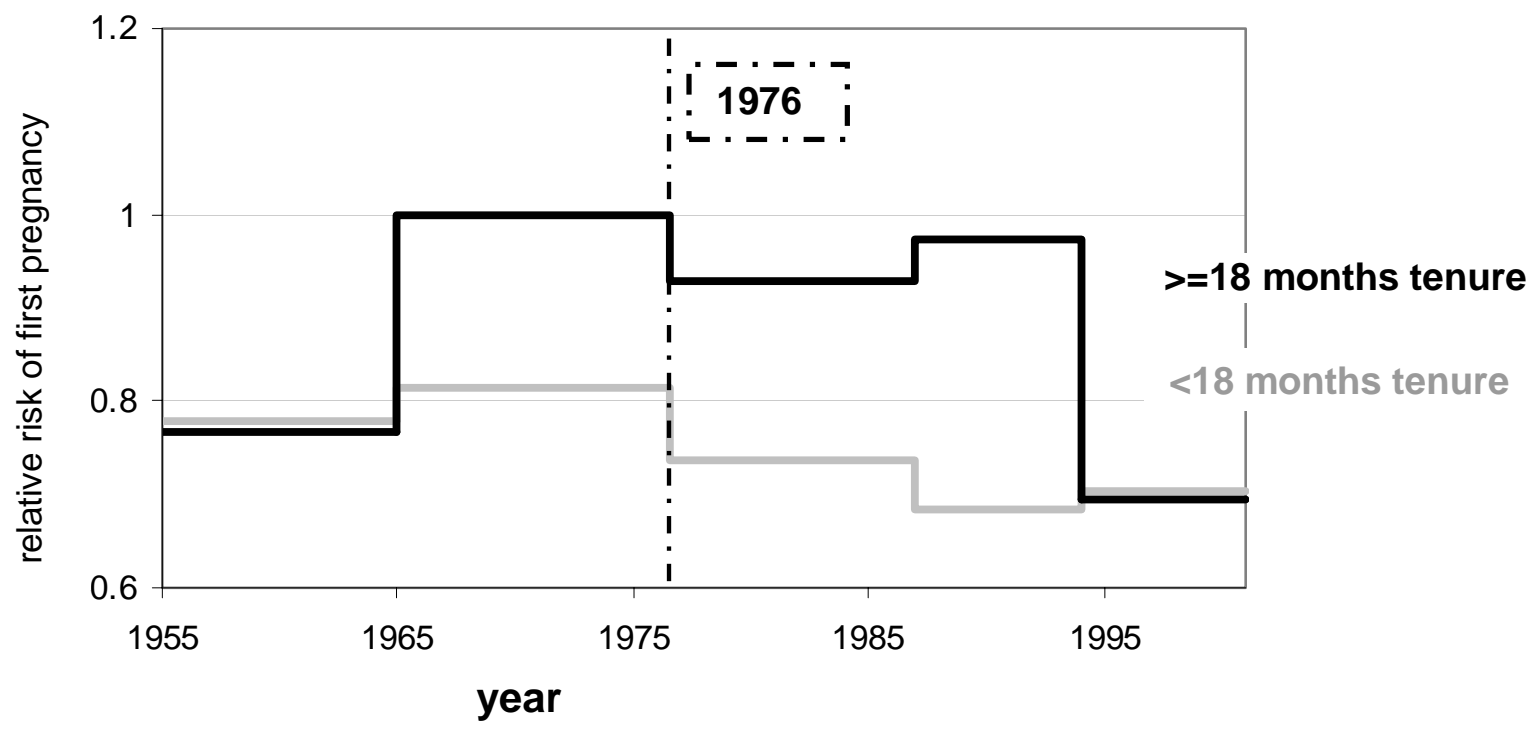




\section{Table 2}

Risk of transition to first pregnancy

age (baseline)

Absolute risk

22-24

0.0108

25-29

0.0113

30-34

0.0079

35-39

0.0031

40-44

0.0005

relative risks

time period (not full-time employed)

1955-1965

1965-1976

1976-87

1.41

1

1987-94

0.91

0.92

$0.59^{* *}$

employment status

self-employed

0.79

full-time employed

part-time employed

1.09

not employed

0.97

employed, status unknown

tenure/ period (full-time employed)

$<18$ months; $1955-65$

0.78

$>=18$ months, $1955-1965$

0.77

$<18$ months; $1965-76$

0.81

$>=18$ months, 1965-1976

$<18$ months; $1976-87$

$>=18$ months, $1976-1987$

$<18$ months; $1987-94$

$>=18$ months, 1987-1994

$<18$ months; 1994-2001

$>=18$ months, 1994-2001

1

0.74 *

0.93

$0.68^{* * *}$

0.97

$0.70^{* *}$

$0.69^{* * \star}$

Education

no/low education

medium education

1.11 *

high education

1

$0.76^{* \star *}$

education missing

0.85

\section{Conclusion}

The results of the empirical investigations presented in this paper indicate that women in Great Britain postponed first birth until they met the employer tenure requirements necessary to qualify for maternity leave. After 1994, when half of maternity leave was made independent of tenure requirements, women no longer postponed first birth to meet the requirements for the second half of maternity leave. Apparently, having the 
right to all 28 weeks of maternity leave was not a strong enough incentive to alter fertility timing, as long as the first 14 weeks of leave as well as 6 weeks of incomerelated maternity pay were available without having to have accumulated any significant amount of employer tenure before pregnancy. Thus, it appears that women adjusted first birth decisions in accordance with changes in maternity leave regulations. This might be taken to demonstrate a high level of importance of the right to maternity leave for women's employment careers.

From a different perspective, it appears that the general decline in rates of transition to first birth was weakened for women employed full-time who qualified for maternity leave. This happened first between 1976 and 1994 for women who fulfilled the necessary tenure requirements for maternity leave. Then after 1994, when there no longer were any tenure requirements and all employees qualified for half of maternity leave, the decline in first birth risks was slowed for all full-time employees.

However, it is not altogether certain whether the introduction of maternity leave was really the cause of changes in timing of first birth by employer tenure in Great Britain. There is evidence that first birth risks began to diverge even before the introduction of maternity leave in 1976 between women who had just begun their jobs and those who had already acquired some employer tenure. Differences in first birth risks by employer tenure were upheld after maternity leave was introduced in 1976, but it is not clear whether this would not have likewise been the case had maternity leave not been introduced.

\section{Acknowledgements}

I would like to thank Michaela Kreyenfeld, Gerda Neyer, Gunnar Andersson, and all the members of the team on institutional and political approaches to family and fertility dynamics for valuable comments and advice. 


\section{References}

Andersson, Gunnar. 2004. Childbearing Developments in Denmark, Norway, and Sweden from the 1970s to the 1990s: A Comparison. Demographic Research Special Collection 3: 154-76.

. 2002. Fertility Developments in Norway and Sweden Since the Early 1960s. Demographic Research 6, no. 4: 67-86.

Andersson, Gunnar, Jan M. Hoem, and Ann-Zofie E. Duvander. 2006. Social Differentials in Speed-Premium Effects in Childbearing in Sweden. Demographic Research 14, no. 4: 51-70.

Department of Trade and Industry. 2006. Parental leave. A short guide for employers and employees URN 06/566. http://www.dti.gov.uk/employment/employment-legislation/employmentguidancelpage18480.html.

2006. Paternity - leave and pay: A basic summary URN No: 06/547. http://www.dti.gov.uk/employment/employment-legislation/employmentguidance/page17139.html.

- 2006. Pregnancy and Work. What you need to know as an employee. Babies due on or after 1 April 2007. http://www.dti.gov.uk/employment/workandfamilies/maternity-leavepay/guidance/page21116.html.

2003. Maternity Rights. A Guide for Employers and Employees. Babies Due on or After April 6 2003. PL 958, no. (Rev 9).

2003. Parental Leave (PL510 Rev 1). A short guide for employers and employees. http://www.dti.gov.uk/er/parental.htm.

2002. Parental Leave. Summary Guidance. $\mathrm{h} t t p: / / w w w . d t i . g o v . u k / e r / i n t g u i d 1 . h t m$, no. Employment Relations.

Dex, Shirley, Heather Joshi, and Susan Macran. 1996. A Widening Gulf Among Britain's Mothers. Oxford Review of Economic Policy 12, no. 1: 65-75.

Dex, Shirley, Heather Joshi, Susan Macran, and Andrew McCulloch. 1998. "Women's Employment Transitions Around Child Bearing." Oxford Bulletin of Economics and Statistics 60(1):79-98.

European Commission. 2002. Family Benefits and Family Policies in Europe. MISSOC-Info 2002, no. 1.

- 2002. MISSOC Comparative Tables on Social Protection in the Member States. Maternity. http://europa.eu.int/comm/employment_social/missoc/2002/uk_part4_en.htm.

Freedland, M. R. 1976. The Employment Protection Act 1975. Individual Aspects. 
The Modern Law Review 39, no. 5: 561-74.

Gauthier, Anne H. and Jan Hatzius. 1997. "Family Benefits and Fertility: An Econometric Analysis." Population Studies 51(3):295-306.

Gregg, Paul, Maria Gutiérrez-Domenech, and Jane Waldfogel. 2003. The Employment of Married Mothers in Great Britain: 1974-2000. Centre for Economic Performance, London School of Economics and Political Science.

Geisler, Esther. 2006. Women's (Re)-Entry into the Labour Market After Childbirth in the United Kingdom. York: University of York (M.A. thesis).

Hoem, Jan M. 1993. Public Policy as the Fuel of Fertiltiy: Effects of a Policy Reform on the Pace of Childbearing in Sweden in the 1980s. Acta Sociologica 36: 1931.

- 1990. Social Policy and Recent Fertility Change in Sweden. Population and Development Review 16, no. 4: 735-48.

McRae, Susan. 1994. "Labour Supply After Childbirth: Do Employers' Policies Make a Difference?" Sociology 28(1):99-122.

. 1993. "Returning to Work After Childbirth: Opportunities and Inequalities." European Sociological Review 9(2):125-37.

1991. Maternity Rights in Britain. London.

Reid, Judith. 1976. Women in Employment. The New Legislation. The Modern Law Review 39, no. 4: 432-51.

Waldfogel, Jane, Yoshio Higuchi, and Masahiro Abe. 1999. "Family Leave Policies and Women's Retention After Childbirth: Evidence From the United States, Britain, and Japan." Journal of Population Economics 12: 523-45. 


\section{Appendix}

Table A1

Occurrences and Exposures

occurrences
(first births)

total

age

22-24

25-29

30-34

35-39

40-45

time period

1955- June 1976

June 1976 - 1994

$1994-2001$

employment status

self-employed

full-time employed

part-time employed

not employed

employed, but status unknown

education

low/ no education

medium education

high education

education missing

1615

1191 tenure / time period (full-time employed)

less than 18 months tenure

1955- June 1976

June 1976 - 1994

$1994-2001$

more than 18 months tenure

1955- June 1976

June 1976 - 1994

$1994-2001$

time period (not full-time employed)

1955-1976

1976-94

1994-2001
613

649

267

76

10

669

761

185

39

95

275

15

593

615

366

41

exposures

(person-months)

227893

68330

69088

39680

27577

23218

86450

104274

37169

8090

167101

13488

37908

1306

77630

80706

63040

6517

103

13586

21887

7504

361

48468

54128

21528

110

205

24396

187

28259

8137 
tenure/ period (full-time employed)

$<18$ months; $1955-65$

4811

$>=18$ months, $1955-1965$

35

22787

$<18$ months; $1965-76$

146

8775

$>=18$ months, 1965-1976

68

25681

$<18$ months; $1976-87$

215

11049

$>=18$ months, $1976-1987$

76

29772

$<18$ months; $1987-94$

239

10838

$>=18$ months, 1987-1994

24356

$<18$ months; 1994-2001

7504

$>=18$ months, 1994-2001

194

21528

time period (not full-time employed)

1955-1965

43

110

1965-1976

107

10203

1976-87

98

14193

1987-94

113

16930

1994-2001

11329

32

8137 